\title{
AGREEMENT WITH CONJOINED ARGUMENTS IN KURIA
}

\author{
Michael Diercks, Lindsey Meyer, \& Mary Paster \\ Pomona College
}

\begin{abstract}
How languages solve the grammatical problem of agreeing with conjoined arguments is a well-known area of cross-linguistic variation. This paper describes these patterns for Kuria (Bantu, Kenya), documenting a pattern of agreement that has not been previously reported. We show the relevant patterns involving a range of noun classes, showing that human noun classes trigger different effects than non-human noun classes. We also demonstrate distinctions in the grammar between subject marking and object marking: whereas subject marking allows for resolved agreement forms, object marking does not. The paper also includes a brief survey of notable patterns in other Bantu languages to put Kuria in a relevant context.
\end{abstract}

Keywords: Kuria, Bantu, morphology, noun classes, syntax

\section{Introduction}

Kuria is a Bantu language (Narrow Bantu E.43) spoken in Southwest Kenya and Northwest Tanzania. It has been the subject of some morphological and phonological research (Cammenga 2004, Mwita 2008, Marlo et al. 2015, Odden 1987), but only recently has Kuria undergone (morpho)syntactic research (Diercks et al. 2015, Ranero et al. 2015, Landman and Ranero 2015, Ranero 2014). Like other Bantu languages, Kuria has an extensive noun class system, with noun class features surfacing on nouns themselves. NPs then trigger agreement (in gender, number, and sometimes person) on other elements in the clause, with verbs being the most prominent. The presence of such rich agreement raises interesting questions for how agreement is determined in instances where, for example, the subject is a conjoined noun phrase, as in (1).
(1) a. John like-s apples.
b. John and Mary like- $\varnothing$ apples

Since English verbal agreement is featurally impoverished, it is relatively straightforward to resolve agreement with conjoined subjects as standard plural agreement. This is less simple for a language like Kuria, however, where noun class (i.e., grammatical gender) is represented in agreement morphology, and therefore differences in the noun classes of conjoined subjects raise questions about what the subject agreement form may be. The example in (2) shows an instance of a conjoined subject with class 3 and class 5 conjuncts, where only the features of the first conjunct are realized in subject agreement:

\section{(2) u-mu-bíírá ní-í-ri-géná -gú-síir:é \\ 3-3-ball and-5-5-stone FOC-3sA-disappear.PF.FV \\ 'The ball and the stone disappeared.'}

\footnotetext{
${ }^{1}$ Orthographic conventions can be found in the appendix.
} 
The first conjunct agreement pattern seen in (2) is just one of several possible strategies Kuria uses to resolve the grammatical problem raised by agreement with conjoined subjects with incompatible feature sets. This paper documents a variety of those patterns to describe the general grammar of agreement with conjoined arguments in Kuria (including both subjects and objects). Given that the main aim of this paper is descriptive, we do not offer a theoretical analysis of the resulting patterns. ${ }^{2}$ There is a fair amount of cross-linguistic research on agreement with conjoined phrases in Bantu, showing significant diversity in the resulting agreement patterns, including research on Swahili (Ashton 1944; Schadeberg 1992; Krifka 1995; Marten 2000, 2005), Sesotho (de Vos and Mitchley 2012), CiNsenga (Simango 2012), Chichewa (Corbett and Mtenje 1987), Luganda and Bemba (Givón 1970, 1972: 80-93), Xhosa (Voeltz 1971), Tswana and Zulu (Roberts and Wolontis 1974), and Dzamba, Likila, and Lingala (Bokamba 1985). Some of these patterns are described below in section 5, with the purpose of placing the Kuria facts in their crosslinguistic context (though a full survey of the cross-linguistic results is beyond the scope of this current paper).

It is important to note that we are not necessarily describing language usage here; it may well be that in practice (as Schadeberg 1992 notes for Swahili) speakers' main strategy is to simply avoid conjoined arguments. Our concern in this paper, however, is to lay out the grammatical patterns of acceptable and unacceptable agreement morphology with different kinds of conjoined arguments in Kuria, leaving questions of individual speaker's preferred strategies to future research. The main data collection occurred in elicitation sessions with a Kuria speaker in Claremont, CA, from January 2013 to November $2013 .^{3}$

The rest of this introductory section lays out the basic relevant morphology on Kuria nouns and verbs. Section 2 discusses conjoined subjects from non-human noun classes, and section 3 tackles conjoined subjects from human noun classes. Section 4 discusses the distinct patterns that arise in object marking with conjoined objects, and section 5 discusses patterns of agreement with conjoined arguments that have been documented for other Bantu languages, with the intention of putting the Kuria facts in a more complete empirical context. Section 6 concludes.

1.1. Basic description of relevant Kuria morphosyntax. The patterns described in this and following sub-sections will be familiar to those who have knowledge of Bantu languages, offered here for those who have less familiarity with the language family. As illustrated in (3), Kuria is a canonically SVO language. ${ }^{4}$ The verbal form follows the familiar Bantu template of subject markers (glossed SA here for 'subject agreement') followed by tense, then optional object markers $(\mathrm{OM})$, and then the verb root. Post-root verbal morphology can include derivational morphology (e.g., applicatives and causatives) and tense/aspect marking, and the obligatory final vowel (FV) can indicate mood.
o-mw-árímú n-aa-néng-ééy-é
1-1-teacher FOC-2SA.PST-give.as.gift-APPL.PF-FV
'The teacher gave the women the clothing.'

\begin{abstract}
á-ba-íséké á-ma-hánga
2-2-women 6-6-clothing
\end{abstract}

(Diercks et al. 2015)

2 Despite our descriptive focus here, the theoretical implications of agreement with conjoined phrases is a matter of much current research: see Benmamoun et. al. 2009, Bošković 2009, Citko 2004, Doron 2000, Munn 1999, Bhatt and Walkow 2012, among others.

3 Our Kuria consultant is a 37-year-old man from Isibania in Migori County, Kenya, which is located on the Tanzania border. He has lived in the US for 9 years but regularly speaks Kuria with family.

4 Postverbal subjects are not possible (to our knowledge), which is relevant to the comparative discussion taken up in section 5. 
As in some nearby languages, canonical declarative clauses in Kuria come with a focus marker that is prefixed to the verbal form ( $n$ - in the example in (3)), and which appears on focused elements and wh-phrases in focus and interrogative contexts. The properties of the focus marker are peripheral to our concerns in this paper and will not be discussed here (see Ranero (2014) and Landman and Ranero (2015)).

As is also evidenced in the example above, Kuria nouns (like most Bantu languages) bear noun class morphology, glossed with cardinal numbers preceding the nominal root (following Bantuist convention). In Kuria, as in many other Bantu languages, there are two prefixes on the noun, often referred to (from left to right) as the pre-prefix (or augment vowel), and the prefix. Subject and object marking frequently reference noun class, as will be shown in the following sections.

1.2. Kuria Noun Classes. The table in (4) shows a partial list of Kuria noun classes with their prefixes and pre-prefixes.

(4) Partial Listing of Kuria Nominal Noun Class Morphology

\begin{tabular}{|l|l|l|l|l|}
\hline NC & Pre-Prefix & Prefix & Example & Gloss \\
\hline 1 & o- & - mo- & omokári & 'woman' \\
\hline 2 & a- & - ba- & abakári & 'women' \\
\hline 3 & o- & - mo- & omoté & 'tree' \\
\hline 4 & e- & - en- & emeté & 'trees' \\
\hline 5 & i- & - ri- & iriigí & 'egg' \\
\hline 6 & a- & - ma- & amagí & 'eggs' \\
\hline 7 & e- & - ke- & egeénto & 'thing' \\
\hline 8 & i- & - bi- & ibiínto & 'things' \\
\hline 9 & e(n)- & $-\varnothing-$ & embégo & 'seed' \\
\hline 10 & i- & - chi(n)- & ichimbégo & 'seeds' \\
\hline
\end{tabular}

Even-numbered noun classes denote plural forms of the immediately preceding odd numbered class. There are various other singular-plural mappings between these classes (for example for diminutives and augmentatives), and additional noun classes beyond class 10 (including locative classes). Cross-linguistically these noun classes frequently show irregular behaviors (e.g., with some classes restricted to abstract nouns, or to mass nouns), or are restricted to particular semantic classes of nouns, for example the locative classes 16-18 that are designated for locations(cf. Cammenga (2004) and Mwita (2008) for details).

Given this broad range of additional patterns beyond noun class 10, we restrict our attention to the subject- and object-marking patternsto classes 1-10 in Kuria (regular singular/plural count nouns). This allows us to establish a baseline for the agreement properties of conjoined arguments, laying the groundwork for future research to investigate the more irregular and specialized noun classes in more depth.

1.3. Basic forms of Subject Marker. Kuria is a null-subject language, and subject agreement is required on all verbs (except imperatives). Subject agreement on the verb is a prefix that accords with the gender, person, and number features of the subject. The subject agreement markers standardly used to refer to humans are shown in (5). 
(5) Person-marked Subject Agreement in Kuria

\begin{tabular}{|l|l|l|l|}
\hline & \multicolumn{2}{|l|}{ Person } & $\mathbf{2}^{\text {nd }}$ \\
\hline & $\mathbf{1}^{\text {st }}$ & o- & a- (class 1) \\
\hline Singular & (e)ne- & mo- & ba- (class 2) \\
\hline Plural & to- &
\end{tabular}

Note that the $3 \mathrm{rd}$ person forms for singular and plural refer to what is traditionally referred to as classes 1 and 2 , respectively. The 3rd person subject agreement markers, including non-human noun classes up to class 10, are shown below in (8), with example sentences in (6) and (7) showing these forms in a sentential context.

(6) u-mu-bíírá y-gú-síir:é

3-3-ball FOC-3SA-disappear.PST.FV

'The ball disappeared.'

(7) u-mu-ísćke n-a-síir:é

1-1-girl FOC-1SA-disappear.PST.FV

'The girl disappeared.'

(8) Partial Listing of Subject Agreement (SA) Forms in Kuria

\begin{tabular}{|c|c|c|c|c|}
\hline NC & Nominal & Verbal & \multicolumn{2}{|c|}{ Example: FOC-SA-disappear.PST } \\
\hline 1 & o-mo- & a- & nasiir:é & 'S/he disappeared.' \\
\hline 2 & a-ba- & ba- & mbasiir:é & 'They disappeared.' \\
\hline 3 & o-mo- & go- & ngusiir:é & 'It (tree) disappeared.' \\
\hline 4 & e-me- & ge- & ygisiir:é & 'They (trees) disappeared.' \\
\hline 5 & i-ri- & re- & ndisiir:é & 'It (stone) disappeared.' \\
\hline 6 & a-ma- & ga- & ngasiir:é & 'They (stones) disappeared.' \\
\hline 7 & e-ke- & ke- & ggisiir:é & 'It (book) disappeared.' \\
\hline 8 & i-bi- & bi- & mbisiir:é & 'They (books) disappeared.' \\
\hline 9 & e-(n)- & e- & nisiir:é & 'It (table) disappeared.' \\
\hline 10 & i-chi(n)- & chi- & nchisiir:é & 'They (tables) disappeared.' \\
\hline
\end{tabular}

The subject markers in the examples given in (8) sometimes vary from the underlying form of the subject marker. This is due to various morphological and phonological rules acting on the underlying forms. These include vowel harmony, assimilation/dissimilation, post-nasal hardening, and deletion, explaining some of the allomorphy (see Cammenga 2004, Mwita 2008, Fischer 2010 for more details on the relevant processes). In canonical cases, subject markers (and object markers, as demonstrated in section 4) match the person, number, and gender (i.e., noun class) of the correlating NP argument. However, these patterns change when looking at conjoined subjects and objects, which we take up in the following sections.

\section{Conjoined Subject Agreement with Non-Human Noun Classes}

When the two nouns in a conjoined subject are from different noun classes, a question arises as to what features will be realized in agreement morphology. Several possibilities arise in Kuria; common solutions include privileging the first or closest conjunct (depending on the class of the 
conjuncts), resolved agreement forms utilizing features from both conjuncts, and default agreement forms. The various contexts for each are discussed in what follows. ${ }^{8}$

2.1. Singular + Singular. When the two conjuncts are singular, it is possible for subject agreement to target the noun class of the first noun — first conjunct agreement (FCA) — as seen in (9).

$\begin{array}{lll}\text { (9) u-mu-bíírá ní-í-ri-géná } & \text { j-gú-síir:é } \\ \text { 3-3-ball } & \text { and-5-5-stone } & \text { FOC-3sA-disappear.PST.FV }\end{array}$

FCA

'The ball and the stone disappeared.'

When both conjuncts are singular, subject agreement may also reflect the plural noun class of the first noun, which we will call the resolved agreement (RES) because it combines the gender (noun class) of the first noun with the plurality of the conjoined subject as a whole. Another subject agreement possibility is to realize a default noun class (class 8), which we will call default agreement (DEF). These two possibilities are shown in (10), where class 4 is the plural of class 3 in (a). For non-human noun classes, it is never possible for the verb to subject-agree with the second conjunct alone, or to adopt the gender of the second conjunct in a resolved agreement, as shown in (11). Last conjunct agreement is labelled LCA. In some instances the first conjunct agreement may be the same as the resolved agreement, which is represented as RES (FCA). When the resolved agreement privileges the features of the last conjunct, we use the label RES (LCA).
(10) a. u-mu-bíírá ní-í-ri-géná y-gí-síir:é RES
3-3-ball and-5-5-stone FOC-4SA-disappear.PST.FV
b. u-mu-bííá ní-í-ri-géná m-bí-síir:é DEF
3-3-ball and-5-5-stone FOC-8SA-disappear.PST.FV
'The ball and the stone disappeared.'
(11) a. *u-mu-biira ni-i-ri-gena n-di-siir:e LCA
3-3-ball and-5-5-stone FOC-5SA-disappear.PST.FV
b. *u-mu-biira ni-i-ri-gena y-ga-siir:e RES (LCA)
3-3-ball and-5-5-stone FOC-6SA-disappear.PST.FV

With RES or DEF agreement indicates that the plurality of the conjoined subject as a whole contributes to the subject marking possibilities in Kuria, even when gender resolution is not possible, suggesting a relative independence between agreement in gender and agreement in number.

2.2. Plural + Singular. When one of the conjuncts is plural, the possibilities for agreement narrow. With a plural first conjunct, agreement on the verb can be with the first conjunct (FCA) or the default class (DEF), shown in (12). Perhaps not surprisingly, agreement is no longer possible with the singular form of the first conjunct, as in (13); any agreement with the second conjunct alone is ruled out.

\footnotetext{
${ }^{8}$ To our knowledge, there are no interpretive differences between the different agreement strategies, but it is possible that there are discourse-oriented pragmatic ones we did not identify.
} 
(12)
a. i-mi-bííá
ní-í-ri-géná
n-gí-síir:é
RES (FCA)
4-4-balls
and-5-5-stone FOC-4SA-disappear.PST.FV
b. i-mi-bíírá
ní-í-ri-géná
m-bí-síir:é
DEF
4-4-balls
and-5-5-stone FOC-8SA-disappear.PST.FV
'The balls and the stone disappeared.'

(13)
*i-mi-biira
ni-i-ri-gena
and-5-5-stone
y-gu-siir:e
FOC-3SA-disappear.PST.FV
$(*$-di-, *-ga-)
$\left(*-5 \mathrm{SA}-,{ }^{*}-6 \mathrm{SA}-\right)$

In this case, the agreement form in (12) could be analyzed as first conjunct agreement or resolved agreement. Note that agreement with the second conjunct is not possible.

2.3. Singular + Plural. When the second conjunct is plural, but the first conjunct is singular, some variation is possibile. In most cases, agreement with the first conjunct (FCA) or the default class (DEF) is found, as in (14).
(14)
ná-á-ma-géná
3-3-ball
and-6-6-stones
m-bí-síir:é
DEF
FOC-8SA-disappear.PST.FV
b. u-mu-biírá ná-á-ma-géná
y-gú-síir:é
FCA
'The ball and the stones disappeared.'

The resolved agreement forms in these cases like the one shown in 0 were routinely judged as less acceptable than the other agreement patterns, though judgments varied for examples like this and therefore were not universally ruled out, as was the case for the second conjunct agreement patterns (we mark this with a \% to signal this variability in judgments)
$\% ? * u-m u-b i i r a ~ n a-a-m a-g \varepsilon n a$ and-6-6-stones
(15) $\%$
y-gi-siir:e
FOC-4SA-disappear.PST.FV
RES (*di-, *ga-)
$(* 5 \mathrm{SA}-, * 6 \mathrm{SA}-)$

The fact that resolved agreement is often unacceptable in this case implies that the second conjunct (specifically its plurality), while not triggering agreement itself, is nonetheless capable of affecting the agreement possibilities overall: when the second conjunct is singular, resolved agreement is wholly acceptable. However, when the second conjunct becomes plural, resolved agreement is consistently deemed less acceptable or ruled out. We will see additional examples in section 3 where second conjuncts factor into agreement possibilities.

2.4. Plural + Plural. When both conjuncts are plural, first conjunct agreement and default agreement are possible, as shown in (16) (notice again here that FCA and RES agreement are indistinguishable when first conjuncts are plural, given the resolution patterns). As with the previous instances, the example in (17) shows the lack of last conjunct agreement.

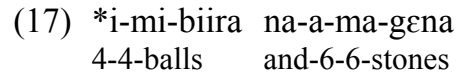
y-ga-siir:e
FOC-6SA-disappear.PST.FV

DEF

\section{RES (FCA)}

$$
\begin{aligned}
& \left(* \text { di- },{ }^{*} \text { gu- }\right) \\
& (* 5 \text { sA-, } \\
& * 3 \mathrm{sA}-)
\end{aligned}
$$


This section shows that when both the nouns in a conjoined subject are from non-human noun classes, agreement can occur with the first conjunct, the default class, or with a resolved agreement that takes into account the noun class of the first conjunct and the plurality of the noun phrase. The exceptional case was when the first conjunct is singular and the second plural, in which case the resolved agreement was degraded. The patterns of conjoined agreement with nonhuman noun classes is summarized below in (18), where RES (FCA) denotes resolved agreement using the gender of the first conjunct, and RES (LCA) denotes resolved agreement using the gender of the second conjunct.

(18) Summary of Conjoined Subjects with Two Non-Human Conjuncts

\begin{tabular}{|l|l|l|l|l|l|l|}
\hline \multicolumn{2}{|l|}{ Conjuncts (Subjects) } & \multicolumn{5}{|c|}{ Can subject agreement use this strategy? } \\
\hline & & FCA & RES(FCA) & DEF & LCA & RES(LCA) \\
\hline \multirow{3}{*}{$\begin{array}{l}\text { Non-human } \\
\text { noun classes }\end{array}$} & sg. + sg. & yes & yes & yes & no & no \\
\cline { 2 - 7 } & pl. + sg. & yes & yes* & yes & no & no \\
\cline { 2 - 7 } & sg. + pl. & yes & no & yes & no & no \\
\cline { 2 - 7 } & pl. + pl. & yes & yes* & yes & no & no \\
\hline
\end{tabular}

- $\quad$ RES and FCA are indistinguishable here.

For the sake of completeness, it is perhaps worth demonstrating that default agreement is not a strategy that is available in cases of non-conjoined subjects, as shown in (20):

(19) i-mi-bíírá y-gí-síir:é

4-4-balls FOC-4SA-disappear.PST.FV

'The balls disappeared.'

(20) *i-mi-biira m-bi-siir:e

4-4-balls FOC-8SA-disappear.PST.FV

The default strategy is therefore a strategy designated for dealing with conjoined clauses of different noun classes, alongside the additional strategies of first conjunct agreement and resolution. The next section shows that default agreement is not possible when one of the conjuncts comes from a human noun class.

\section{Conjoined Subject Agreement with Human Noun Classes}

When one of the nouns in a conjoined subject is from the human noun classes (1\&2), the possibilities for agreement change. Crucially, the order of the conjuncts becomes irrelevant for agreement, and the privileged conjunct becomes the class $1 / 2$ conjunct; the human noun classes are prioritized and trigger agreement whenever available. This pattern is evident in (21) and (22). Example (21) shows that when the first conjunct is from class 1 the same patterns of agreement are possible as with non-human noun classes (first conjunct agreement and resolved agreement), with the exception of default agreement, which is always ruled out with a class 1 or 2 conjunct.

(21) a. u-mu-ísćke ne-e-m-bźbá n-á-síir:é 1-1-girl and-9-9-mouse FOC-1SA-disappear.PST.FV

b. u-mu-ísćke ne-e-m-bébá m-bá-síir:é

1-1-girl and-9-9-mouse FOC-2SA-disappear.PST.FV

FCA

'The girl and the mouse disappeared.'

RES (*e-, *chi-, *bi)

(*9SA-, *10SA-, $\left.{ }^{*} 8 \mathrm{SA}-\right)$ 
As can be seen in (22), when the second conjunct is class 1, last conjunct agreement (or a resolved agreement drawing its gender from the last conjunct) occurs.
a. ${ }^{\%}$ e-m-bébá nú-u-mu-ísćké
9-9-mouse and-1-1-girl
b. e-m-bźbá nú-u-mu-ísćké
9-9-mouse and-1-1-girl
n-á-síir:é
FOC-1SA-disappear.PST.FV
m-bá-síir:é
FOC-2SA-disappear.PST.FV
LCA
'The mouse and the girl disappeared.'
RES (LCA)
$(* \mathrm{e}-$, *chi-, *bi-)
$\left(* 9 \mathrm{SA}-, * 10 \mathrm{SA}-,{ }^{*} 8 \mathrm{SA}-\right)$

As can be seen from both (21) and (22), it is not possible in these contexts to have agreement with the singular or plural form in the gender (noun class) of the non-human conjunct, nor is agreement with the default class 8 possible. Note that the first example in (22) is marked \% to note some variability in judgments across elicited examples with this agreement pattern. The pattern was usually judged as acceptable by the speaker, but in some cases it was degraded, without a clear explanation (though it is probably significant that this variability only arose when the human conjunct was the second conjunct). This variability could be a valuable area for additional research.

These patterns of agreement are seen with any combination of singular and plural nouns combining human and non-human noun classes. Similar to agreement with non-human noun classes, when the human noun is plural, only agreement with the plural human marker is possible, as seen in (23). As with the previous examples, the default class 8, singular agreement, and any agreement governed by the non-human noun class is ruled out.
a. e-m-bébá ná-á-ba-ísćké m-bá-síir:é
9-9-mouse and-2-2-girls FOC-2SA-disappear.PST.FV
'The mouse and the girls disappeared.'
b. *e-m-beba na-a-ba-iscke m-bi-siir:e
9-9-mouse and-2-2-girls FOC-8SA-disappear.PST.FV

\author{
RES (LCA) \\ $\left(* \mathrm{e}-,{ }^{*}\right.$ chi-, *a-) \\ $\left(* 9 \mathrm{SA}-,{ }^{*} 10 \mathrm{SA}-,{ }^{*} 1 \mathrm{SA}-\right)$
}

The same verbal agreement patterns as those in (23) are seen when the class 2 noun occurs as the first conjunct. In general, the presence of a class $1 / 2$ conjunct eliminates the prominence of the first conjunct that we saw in the preceding section.

The same pattern occurs when one of the nouns is a local pronominal form: agreement with the person features of the pronominal conjunct takes priority over agreement with the non-human noun class, even if the non-human noun is the first conjunct. As with class 1 ( $3 \mathrm{sg}$, human) conjuncts, when the personal pronoun is singular, as in (24)a, agreement can be with the first person singular second conjunct or appear as the resolved form (again, a resolved form that privileges the second conjunct, retaining person from the second conjunct and plurality from the conjoined subject as a whole).
a. e-m-bébá
na ní n-ín-síir:é
9-9-mouse
and 1 sg FOC-1sgSA-disappear.PST.FV
9-9-mouse and 1sg FOC-1plsA-disappear.PST.FV
'The mouse and I disappeared.'

\author{
LCA \\ RES (LCA) (*e-, * chi-, *bi-) \\ (*9SA-, *10SA-, *8SA-)
}

The plural pronouns behave in the same manner as singular pronouns, showing only lastconjunct agreement (or, the identical trivially resolved plural agreement) and ruling out default agreement forms and any agreement where the gender is controlled by the non-human conjunct.
a. e-m-bćbá
ná baitó
n-tú-síir:é
9-9-mouse
and $1 \mathrm{pl}$
FOC-1plsA-disappear.PST.FV
b. *e-m-beba na baito m-bi-síir:é

RES (LCA)

(*e-, *chi-, *im-) 
9-9-mouse and $1 \mathrm{pl}$ FOC-8sA-disappear.PST.FV

'The mouse and we disappeared.'

$\left(* 9 \mathrm{SA}-,{ }^{*} 10 \mathrm{SA}-,{ }^{*} 1 \mathrm{sgSA}-\right)$

In (24) and (25), the local pronoun could be the first conjunct and the agreement possibilities on the verb would be the same. These are of course expected resolutions of feature sets, where any non-singleton set of individuals that contains the speaker is considered 1st person plural, a familiar cross-linguistic pattern.

When both of the conjuncts are human, subject agreement is resolved as might be expected on the basis of the features of both conjuncts, regardless of order, as shown in (26).
(26) a. Mokámí na ní n-tú-síir:é
1Mokamiand 1sg FOC-1plsA-disappear.PST.FV
b. oní ná Mókámí n-tú-síir:é
$1 \mathrm{sg}$ and 1Mokami FOC-1plsA-disappear.PST.FV
'Mokami and I disappeared.'
RES (*en-, *a-, *ba-)
$(* 1$ sgSA,$- * 1 \mathrm{SA}-, * 2 \mathrm{SA}-)$
RES (*en-, *a-, *ba-)
$(* 1$ sgSA-, $* 1$ SA-,$* 2 \mathrm{SA}-)$

Subject agreement in 1sg, $3 \mathrm{sg}$ (class 1), or 3pl (class 2) is not possible in this case. Either noun in the conjoined subjects in (26) could be pluralized and the agreement on the verb would not change, again as is expected by the standard operation of person agreement in Kuria (identical to familiar languages like English in these cases).

When both arguments are local pronouns, the expected patterns of resolution occur: for example, conjoining a $2^{\text {nd }}$ or $3^{\text {rd }}$ person pronoun with a first person pronoun produces $1^{\text {st }}$ plural agreement forms:

(27) wé na ní n-tú-síir:é

$2 \mathrm{sg}$ and $1 \mathrm{sg}$ FOC-1plsA-disappear.PST.FV

'You and I disappeared.'

(28) wé na ní n-tú-síir:é

$3 \mathrm{sg}$ and $1 \mathrm{sg}$ FOC-1plsA-disappear.PST.FV

'He and I disappeared.'

Likewise, a $2^{\text {nd }}$ person form conjoined with a $3^{\text {rd }}$ person form results in a $2^{\text {nd }}$ plural subject agreement form:

(29) wé na wé mú-síir:é
$2 \mathrm{sg}$ and 3sg FOC.2plsA-disappear.PST.FV
'You and he disappeared.'

Tthis section shows that when one of the nouns in a conjoined subject is from a human noun class ( 1 or 2 ) or using a local person feature ( $1^{\text {st }}$ or $2^{\text {nd }}$ person), agreement with the human conjunct takes precedence over non-human conjuncts, and agreement with person-marked conjuncts takes priority over any other sort of conjunct, at least with respect to what gender/person features will be realized in the subject agreement. Person features of conjoined pronouns combine in expected fashion to produced person-/number-resolved subject agreement forms. When both conjuncts are human, agreement can only be with the resolved features of the combined group; default agreement forms are unacceptable across the board with human subjects. We summarize the patterns for conjoining human noun classes in (30) (leaving out human+human, which generates expected kinds of resolved agreement forms, as there are no feature conflicts):

(30) Summary of Subject Agreement Patterns with Subjects with One Human Conjunct 


\begin{tabular}{|c|c|c|c|c|c|c|}
\hline \multicolumn{2}{|c|}{ Conjuncts (Subjects) } & \multicolumn{5}{|c|}{ Can subject agreement use this strategy? } \\
\hline & & FCA & RES(FCA) & DEF & LCA & RES(LCA) \\
\hline \multirow{8}{*}{$\begin{array}{l}\text { Non-human NC + } \\
\text { human NC (1/2) }\end{array}$} & $\mathrm{Cl} .1+\mathrm{sg}$ & yes & yes & no & no & no \\
\hline & $\mathrm{Cl} .2+\mathrm{sg}$ & yes & $\begin{array}{l}\text { yes } \\
(=\text { FCA })\end{array}$ & no & no & no \\
\hline & $\mathrm{sg}+\mathrm{Cl} 2$ & no & no & no & $\begin{array}{l}\text { yes } \\
(=\text { RES } \\
(\text { LCA }))\end{array}$ & yes \\
\hline & $\mathrm{sg}+\mathrm{Cl} .1$ & no & no & no & mixed & yes \\
\hline & $\mathrm{Cl} .1+\mathrm{pl}$ & yes & yes & no & no & no \\
\hline & $\mathrm{Cl} .2+\mathrm{pl}$ & yes & $\begin{array}{l}\text { yes } \\
(=\text { FCA })\end{array}$ & no & no & no \\
\hline & $\mathrm{pl}+\mathrm{Cl} 2$ & no & no & no & $\begin{array}{l}\text { yes } \\
(=\text { RES } \\
(\mathrm{LCA}))\end{array}$ & yes \\
\hline & $\mathrm{pl}+\mathrm{Cl} .1$ & no & no & no & yes & yes \\
\hline
\end{tabular}

\section{Object Marking with Conjoined Objects}

This section demonstrates that object marking of conjoined objects manifests itself very differently from subject agreement with conjoined subjects. Kuria objects may be morphologically represented by a prefix on the verb, (a clitic inDiercks et al. 2015). This prefix must occur following tense morphology (which itself follows subject agreement), but preceding the verb root. Unlike subject agreement, object marking (OMing) is not obligatory, and in fact, object markers can only co-occur with in situ objects in specific situations, described below. We give two examples of OMing in an appropriate (brief) discourse context here, along with a third example of an object marker (OM) with a conjoined antecedent, showing that the OM can bear the same feature set as the resolved subject agreement with the antecedent itself.

(31) u-mu-ísćke n-aa-síir:é

tee-n-kú-mú-maah-a

1-1- $\quad$ FOC-1SA.PST-disappear.PST.FV NEG-1sgSA-INF-1OM-see-FV

'The girl disappeared. I do not see her.'

(32) e-m-bébá yaa-síir:é tee-n-kó-gé-maah-a

9-9-mouse 9SA.PST-disappear.PST.FV NEG-1sgSA-INF-9OM-see-FV

'The mouse disappeared. I do not see it.'

$\begin{array}{llll}\text { (33) u-mu-ísćke ne-e-m-bćbá } & \text { m-bá-síir:é } & \text { tee-n-kó-bá-maah-a } \\ \text { 1-1-girl } & \text { and-9-9-mouse } & \text { FOC-2SA-disappear.PST.FV } & \text { NEG-1sgSA-INF-2OM-see-FV }\end{array}$

'The girl and the mouse disappeared. I do not see them.'

A partial paradigm for Kuria OMs is shown in (34), again restricted to the core noun classes being considered in this paper (1-10).

(34) Partial Listing of Object Marker (OM) Forms in Kuria

\begin{tabular}{|l|l|l|l|l|}
\hline NC & $\begin{array}{l}\text { Nominal } \\
\text { Prefixes }\end{array}$ & OM & Example: FOC-1SA-OM-disappear.PST \\
\hline 1 & o-mo- & mo- & namorekééye & 'S/he threw him/her.' \\
\hline 2 & a-ba- & ba- & nabarekééye & 'S/he threw them.' \\
\hline
\end{tabular}




\begin{tabular}{|l|l|l|l|l|}
\hline 3 & o-mo- & go- & nagorekééye & 'S/he threw it (ball).' \\
\hline 4 & e-me- & ge- & nagerekééye & 'S/he threw them (balls).' \\
\hline 5 & i-ri- & re- & narerekééye & 'S/he threw it (stone).' \\
\hline 6 & a-ma- & ga- & nagarekééye & 'S/he threw them (stones).' \\
\hline 7 & e-ke- & ke- & nakerekééye & 'S/he threw it (book).' \\
\hline 8 & i-bi- & bi- & nabirekééye & 'S/he threw them (books).' \\
\hline 9 & e-(N)- & ge- & nagerekééye & 'S/he threw it (snake).' \\
\hline 10 & i-chi(N)- & chi- & nachirekééye & 'S/he threw them (snakes).' \\
\hline
\end{tabular}

Object markers are not obligatory on the verbal form in Kuria, and can be used for anaphoric reference to a discourse antecedent (as in examples (31)-(33)). While anaphoric use of OMs mirrors the previous agreement forms with those elements (as seen in (33)), interesting patterns arise in instances of an object marker co-occurring with an in situ object (OM-doubling). OMdoubling is the subject of extensive syntactic research in Bantu languages (see Riedel 2009 for an overview). In Kuria OM-doubling can only occur in particular situations, in particular, when an additional object marker appears outside the doubled object marker(s) on the verb, a pattern referred to as an $n+1$ effect of OM-doubling by Diercks et al. (2015) and Ranero et al. (2015). Therefore, it is impossible to have an $\mathrm{OM}$ and an object co-occur in a monotransitive sentence, as shown in (35) (Diercks et al. 2015: 52ff):
a. n-aa-tém-ér-é ó-mo-gámbi FOC.1 sgSA.PST-hit-PF-FV 1-1-king 'I hit the king.'
b. *n-aa-mo-tem-er-e o-mo-gambi FOC.1 1sgSA.PST-1OM-hit-PF-FV 1-1-king 'I hit the king.'

On the other hand, it is possible to have an OM co-occur with (i.e., double) a co-referential object in ditransitive sentences, provided that an additional undoubled OM appears as the outermost (i.e., leftmost) OM on the verb, as the class 2 ba- OM does in (b):
a. o-mo-múrá n-aa-kóbéés-ír-í
$\begin{array}{ll}\text { í-chim-bíríá á-ba-íséke } \\ \text { 10-10-money } & \text { 2-2-girls }\end{array}$
1-1-man FOC.1SA-PST-lend-PF-FV

'The man lent the girls money.'

b. o-mo-múrá n-aa-bá-chí-kóbéés-ír-í

\section{í-chim-bíría}

1-1-man FOC.1SA-PST-2OM-10OM-lend-PF-FV

'The man lent them (the girls) the money.'

\section{0-10-money}

But doubling the outermost object marker is unacceptable, illustrated here with an attempt to double both objects of a ditransitive (see Diercks et al. 2015 for a fuller discussion of the relevant patterns). ${ }^{21}$

\footnotetext{
${ }^{21}$ The relative ordering of the object markers and the objects does not change our speaker's judgments on the acceptability of doubling two objects.
} 
(37) *o-mo-koro n-aa-ba-chi-haa-y-e 1-1-man FOC.1SA-PST-2OM-10OM-lend-PF-FV i-chim-biria a-ba-iseke

10-10-money 2-2-girls

The preceding examples serve to establish the general pattern of object marking in Kuria. It is a question of ongoing research what the interpretive consequences of OM-doubling are in Kuria, which varies widely among related languages.

The examples below recreate the relevant context described above that licenses doubling an $\mathrm{OM}$ and an in situ object, namely, contexts with an additional undoubled OM as the outermost object marker. When OMs double a conjoined object, both conjuncts are object marked separately on the verb, as seen in (38). Note that the first (undoubled class 7) object marker refers to a discourse-familiar class 7 object egekebi 'knife.'
(38) Mokámí
n-aa-ké-ré-gé-kéb-ééy-é
1Mokami FOC-1SA.PST-7OM-50M-9OM-cut-APPL.PF-FV
'Mokami cut the fruit and meat with it (knife).' 22

\section{í-ri-íkó ní-i-nyáma \\ 5-5-fruit and-9-meat}

In (38), the object markers for the two conjuncts appear separately on the verb. The order of object markers in (38) corresponds to the order of the two conjuncts, but the order of the object markers can also be switched without reordering the conjuncts of the object, as in (39). ${ }^{23}$
Mokámí
n-aa-ké-gé-ré-kéb-ééy-é
í-ri-íkó ní-i-nyáma
1Mokami FOC-1SA.PST-7OM-9OM-50M-cut- APPL.PF-FV
5-5-fruit and-9-meat
'Mokami cut the fruit and meat with it (knife).'

It is critical, however, that object markers corresponding to both of the conjuncts be present on the verb; object marking only one of the conjuncts is not acceptable, as shown for the first conjunct of the object in (40) and for the second conjunct in (41).
(40) *Mokami
n-aa-ke-re-keb-eey-e
i-ri-iko
ni-i-nyama
1 Mokami
FOC-1 SA.PST-7OM-5OM-cut- APPL.PF-FV
5-5-fruit
and-9-meat
(41) *Mokami
n-aa-ke-ge-keb-eey-e
i-ri-iko
ni-i-nyama
Mokami
FOC-1 SA.PST-7OM-9OM-cut- APPL.PF-FV
5-5-fruit
and-9-meat

Recall that this is tnotably different from the subject agreement cases, where first conjunct agreement was regularly available with non-human noun classes. Recall also from subject agreement forms that a resolved agreement adopting the noun class of the first conjunct and the plurality of the entire conjoined noun phrase was regularly available when two non-human noun classes were conjoined. As is shown below, object marking a plural form adopting the noun class of either conjuncts is not possible.
*Mokami
n-aa-ke-ga-keb-eey-e
i-ri-iko
ni-in-ama
1Mokami
FOC-1 SA.PST-7OM-60M-cut- APPL.PF-FV
5-5-fruit
and-9-meat

(43)
*Mokami
n-aa-ke-chi-keb-eey-e
i-ri-iko
ni-in-ama
1 Mokami
FOC-1SA.PST-7OM-10OM-cut- APPL.PF-FV
5-5-fruit and-9-meat

\footnotetext{
${ }^{22}$ This and the following examples are in the remote past, which assigns $\mathrm{H}$ tone to the first mora of the macrostem rather than the third as in the recent past examples seen earlier.

${ }^{23}$ Note that the free order of OMs on the verb (irrespective of their argument structure or the order of objects post-verbally) is a general property of OMs distinct from issues relating to conjoined objects (Diercks et al. 2015).
} 
The unacceptability of (42) and (43) reinforces the generalization that both OMs must be represented on the verb (showing that the problem with (40) and (41) is not simply the incorrect form of the relevant $\mathrm{OM}$ ). No matter what the explanation is, the main conclusion here is that the OMing patterns when OMs co-occur with conjoined objects are distinct from what occurs with subject agreement: two OMs occur (as opposed to one SA morpheme) and the SA-like patterns of resolved agreement are ruled out. ${ }^{24}$

Furthermore, note that doubling the $\mathrm{OM}$ with a postverbal object is necessary in the case that OMs for both conjuncts appear on the verb. Marking of the two conjuncts on the verb without doubling the objects is unacceptable. ${ }^{25}$

(44) *Mokami n-aa-ke-ge-re-keb-eey-e

1Mokami FOC-1SA.PST-7OM-9OM-50M-cut-APPL.PF-FV

Intended: 'Mokami cut them with it.'

It is in fact possible for the object marker to occur in the default class 8 in order to impart the intended meaning from above, as shown in (45):
Mokámí
n-aa-ké-bí-kéb-ééy-e
(*i-ri-iko n-i-nyamu)
1Mokami FOC-1SA.PST-7OM-8OM-cut-APPL.PF-FV (*5-5-fruit and-9-meat $)$
'Mokami cut them (fruit and meat) with it (knife)'

\section{DEF}

As noted above, however, OM-doubling with a conjoined object cannot occur with a class 8 $\mathrm{OM}$. The overall pattern that we see with conjoined objects is that object markers may mark each object separately in the case that the object markers co-occur with the in situ conjoined object, or object marking may be in the default class in the absence of OM-doubling, but those patterns cannot be intermixed.

\section{Cross-Bantu Patterns of Agreement with Conjoined Arguments}

In the preceding sections we have documented the range of patterns of agreement with conjoined arguments in Kuria, showing the following patterns. We summarize these patterns in a different chart form here, to include the different properties of object markers, and to state the generalizations in an accessible way:

\footnotetext{
${ }^{24}$ As a reviewer notes, the explanation for the patterns in (42) and (43) could be found in a requirement to represent both OMs, rather than having anything to do with FCA.

${ }^{25}$ Our speaker attributes this unacceptability to too much ambiguity; this may well be the case, as a variety of imbrication processes for post-root morphology on verbs makes the spelled-out forms of verbs often ambiguous as to whether they are applicative, causative, or some combination of the two. In this instance, then, adding object markers to the verb can potentially lead to a new reading of the verb itself, perhaps that an applicative had been added with no overt morphological consequences.
} 
(46) Summary of Kuria Agreement with Conjoined Arguments

\begin{tabular}{|l|l|l|}
\hline Context & Conjuncts & Agreement Forms \\
\hline $\begin{array}{l}\text { Subject } \\
\text { Agreement }\end{array}$ & $\begin{array}{l}\text { Two non-human noun class } \\
\text { conjuncts }\end{array}$ & $\begin{array}{l}\text { First conjunct agreement } \\
\text { Resolved agreement (takes gender from first conjunct) } \\
\text { Default agreement (Class 8) }\end{array}$ \\
\cline { 2 - 3 } & $\begin{array}{l}\text { One human noun class } \\
\text { conjunct and one non- } \\
\text { human }\end{array}$ & $\begin{array}{l}\text { Agreement with human argument (FCA or LCA) } \\
\text { Resolved agreement (class 2, gender from human } \\
\text { conjunct) } \\
\text { *Default agreement (Class 8) }\end{array}$ \\
\cline { 2 - 3 } & Two human conjuncts & $\begin{array}{l}\text { First conjunct agreement } \\
\text { Resolved agreement (gender/person resolved from group) } \\
\text { *Default agreement (Class 8) }\end{array}$ \\
\hline $\begin{array}{l}\text { Object } \\
\text { marking }\end{array}$ & $\begin{array}{l}\text { Two non-human noun class } \\
\text { conjuncts }\end{array}$ & $\begin{array}{l}\text { Both conjuncts realized as object markers on the verb (in } \\
\text { contexts where doubling an OM is possible) } \\
\text { Default class 8 OM is possible (without doubling) }\end{array}$ \\
\hline
\end{tabular}

Without any engagement with the kinds of patterns that exist in related languages, however, it can be difficult to interpret the relative novelty (or not) of the patterns reported here. Therefore, in this section we briefly address some of the existing literature on agreement with conjoined arguments, with the purpose of putting the Kuria facts in context.

5.1. Swahili. A variety of researchers have worked on agreement with conjoined arguments in Swahili, including Ashton (1944), Schadeberg (1992), Krifka (1995), Marten (2000, 2005). Though the authors are not all explicit about the particular varieties of Swahili they are referring to, there is generally consensus about the overall patterns of agreement, which yield various options as summarized below:

(47) Patterns of conjunct agreement in Swahili

- Default agreement (class 8, class 10 for some speakers)

- Last conjunct agreement ${ }^{26}$

○ preverbal subjects with subject agreement

○ fronted objects with object agreement

- First conjunct agreement

○ postverbal subjects with subject agreement

○ postverbal objects with object agreement

- Resolved agreement (for conjuncts of the same noun class, the corresponding plural agreement)

What we see then is that there are clear adjacency effects in Swahili - the closest conjunct to the verb is capable of triggering agreement on the verb (in the appropriate contexts), meaning that word order of the verb with respect to its agreement trigger yields either first conjunct agreement or last conjunct agreement, whichever conjunct is closest to the verb. This is true of subject agreement (depending on whether the subject is preverbal or postverbal) and true of object

${ }^{26}$ Marten (2005) notes that when two class 1 NPs are conjoined in a preverbal subject, only the corresponding plural subject agreement (class 2) is possible. There does not appear to be complete data available as to whether this is true for all conjoined preverbal subjects of the same noun class, or whether it is distinctive of class 1 (humans). Multiple authors note that last conjunct subject agreement is possible for conjoined preverbal subjects, but the examples provided all appear to be conjuncts of different noun classes (and, notably, non-human noun classes). 
marking as well. While we don't have examples of postverbal subjects for Kuria (to our knowledge they are not possible, but this has not been investigated in extended discourse contexts), in general it appears that the adjacency patterns that allow for closest conjunct agreement in Swahili are unattested in Kuria, which instead prefers either first conjunct agreement or some kind of resolved/default agreement. Default agreement forms are also possible in Swahili for instances of gender conflicts between conjuncts, as we saw for Kuria. Multiple sources mention that there can be inter-speaker variation in terms of which strategies are preferred, also noting that some speakers simply avoid such sorts of sentences altogether (Schadeberg 1992).

5.2. Sesotho. De Vos and Mitchley (2012) investigate agreement with conjoined subjects in Sesotho (Lesotho and South Africa, S.33), restricting themselves to conjoined subjects in preverbal position. De Vos and Mitchley's (2012: 6) summary of the Sesotho patterns is given below (where 'balanced' refers to instances of conjuncts from the same noun class):

(48) Patterns of conjoined agreement in Sesotho

For NC-balanced conjuncts:

(a) Coordinated singular DPs take a 'default' plural SM, that is either $d i$ - (non-human) [class 8] or $b a$ - human) [class 2] depending on the animacy of conjuncts.

(b) Coordinated plurals take the expected plural SM for the relevant NC.

(c) Exceptions are NC-balanced [+HUMAN] coordination for NC8 and NC10 which take $b a$-, instead of $d i$-, which is the expected SM for these noun classes.

For NC-unbalanced conjuncts:

(d) Singulars and plurals take 'default' agreement, that is either di- [class 8] or ba- [class 2] depending on animacy of the conjuncts. Conjunctions of [+HUMAN] and [HUMAN], however, yield inconsistent results and/or ineffability.

In Sesotho the primary strategies for dealing with agreement with conjoined phrases are to use a default plural agreement, class 2 with noun phrases denoting humans in the conjuncts (regardless of their particular noun class, e.g., the class 10 noun dingaka 'doctor'), and to use a default class 8/10 marker for non-human conjuncts. Conjunction of non-human and human nouns is regularly deemed unacceptable. De Vos and Mitchley do note that conjunctions of classes 4 and 6 routinely produced inconsistent results of varied subject agreement strategies from their speakers, but leave that issue for future research. Sesotho is similar to Kuria and Swahili in employing default agreement forms, but diverges in that Sesotho appears to disallow agreement with individual conjuncts, or resolved agreement forms (for the most part), whereas both Kuria and Swahili allow for strategies for agreement with conjunctions that are 'unbalanced' with respect to noun class (though not identical strategies).

5.3. CiNsenga. Simango (2012) discusses patterns of agreement with conjoined phrases in CiNsenga (Zambia and Malawi, N.41); the observations made in that work are summarized in (49):

(49) Patterns of conjoined agreement in CiNsenga

- A default agreement (class 8) when two non-human singular nouns are conjoined.

- The expected plural agreement when two non-human plural nouns of the same noun class are conjoined.

- Resolved class 2 agreement when a class 1 noun is conjoined with a non-human noun.

- Word order effect: a subject of conjoined singular NPs (triggering default class 8 agreement) can only occur in preverbal position. 
- Word order effect: a subject of conjoined plural NPs (triggering corresponding plural subject agreement) can occur preverbally or postverbally.

- Word order effect: a subject of conjoined human NPs triggering plural class 2 agreement can occur preverbally or postverbally.

Like Kuria, CiNsenga allows for resolved agreement forms between a human conjunct and a non-human conjunct, resolving to class 2 (it is not clear from the data reported whether this pattern of resolution extends to other NC-unbalanced conjunctions). And like all the other languages discussed here, CiNsenga allows for default agreement forms in at least some contexts. CiNsenga, like Swahili, shows effects of word order, though the particular effects here are highly constrained compared to Swahili, depending on the particular kinds of nouns that are conjoined (and agreement triggered). We have not noted such word order effects in Kuria, not having documented instances of postverbal subjects, though we do not rule out the possibility that postverbal subjects are possible.

5.4. Kuria Patterns of Conjoined Agreement, in Context. There are a variety of other documented patterns in other Bantu languages: Voeltz (1971) reports that Xhosa in fact disallows instances of conjoined arguments of different genders when those conjunctions are realized on the verb in some way (subject or object marking). The Xhosa constraint presumably arises out of the problem of morphologically realizing the relevant features, as agreement with conjunctions is not ruled out only in those instances where there is syncretism between the agreement forms for the different conjuncts. Corbett and Mtenje (1987) report for Chichewa that any conjunction of nonhuman singular NPs in subject position requires a default class 8 marker (even when the singular conjuncts are of the same class). They also find a result similar to Voeltz, that conjunction of NPs that takes the same plural agreement morphology does occur (even if the conjuncts are themselves of different classes). Therefore we see in many instances that post-syntactic concerns of feasibility of morphological realization of a particular set of features plays an important role.

There are still more reports of agreement with conjoined phrases in other Bantu languages, for example Givón 1970, 1972 on Luganda and Bemba, Bokamba (1985) on Dzamba, Likila and Lingala, Mateene (1980: 332-333) on Nyanga, and Roberts and Wolontis 1974 on Tswana and Zulu.

An additional observation that arises from the literature (though not from this particular study) is that there are often individual differences between different speakers with respect to their judgments about agreement forms with conjoined arguments. While any particular set of judgments is useful idiolectal data, it may well be that some (or many) language grammars (and primary linguistic data) are simply underspecified at the point of acquisition with respect to the grammar of agreement with conjoined phrases, allowing individuals to settle on different idiolects.

In addition to putting the Kuria facts in context, this review shows that different languages use different strategies to deal with agreement with conjoined arguments, but similar kinds of pattterns arise across languages, some familiar to Kuria. The presence of default agreement forms in certain contexts is a familiar pattern that arises in most of the languages reported (with Xhosa as a major exception). Resolved agreement forms are common as well, though the particular patterns of resolution vary from language to language. As Corbett and Mtenje mention (and has been reported cross-linguistically), closest conjunct agreement is common, as discussed above for Swahili, which is a point where Kuria (and perhaps Zulu (Martin Walkow, pc)) diverges, largely preferring first conjunct agreement. It is important to note (particularly for theoretical work based on conjoined agreement) that a very common result reported in the literature is that certain combinations of gender in conjoined arguments/subjects are unacceptable (i.e., ineffable, to use de 
Vos and Mitchley's term). We largely did not encounter these concerns with the Kuria speaker who supplied the judgments for this project.

The object-marking pattern reported here is wholly new, to the best of our knowledge. Object marking itself is an issue of intensive analytical and theoretical debate (Bresnan and Mchombo (1987), Marten et al. (2007), Riedel (2009), Bax and Diercks (2012); see Diercks and Sikuku (2015) for a survey of concerns in Bantu).. The explanation of the pattern of conjoined object marking is surely contingent on the conclusions here and in Bantu more generally (see Diercks et al. 2015, Ranero et al. 2015 for discussion of the issues for Kuria). The pattern reported here (of realizing object markers for both conjuncts) is very different from the pattern reported for Swahili above, which simply object-marked the closest conjunct. The focus of most works on conjoined agreement is on subject marking; in many ways the relevant comparative data is simply underreported at present.

As is always the case, individual grammatical differences between languages (e.g., the (non)availability of postverbal subjects or the grammar of object marking) make direct comparisons of every pattern impossible. Additionally, especially with such a multitude of potential contexts to test, it is surely the case that each researcher did not examine identical combinations of agreement possibilities. There are methodological distinctions, too, that are relevant for the kinds of descriptions that arise: for example, Marten (2000) relies mainly on discourse examples drawn from a novel, whereas this paper relies on data produced by elicitation. Marten's work likely sacrifices a certain degree of grammatical completeness given the availability and pragmatic plausibility of certain exemplars of conjoined arguments, whereas our work sacrifices some real-world plausibility/naturalness for grammatical completeness. Both sorts of methodologies are important for proper documentation and analysis of both the grammar and usage with respect to agreement with conjoined arguments.

\section{Conclusion}

In this paper we presented the different patterns of conjoined agreement forms in Kuria, arriving at the empirical generalizations summarized in (46) above. The data in this paper add to the field's knowledge of agreement with conjoined arguments, providing a rich data set on agreement with conjoined arguments from an understudied language. It is important to note that relatively little research has been done on the structure of the conjoined phrases themselves in these languages (to our knowledge), which complicates somewhat any conclusions reached about the consequences of patterns like these for theories of agreement without additional research into the structure of conjunction in the relevant languages. Nonetheless, these data may well be useful for clarifying and refining theories of syntactic agreement, and marks progress toward better documentation of Kuria, though much work remains to be done.

\section{Acknowledgments}

First, we would like to thank Johnes Kitololo for his incredible patience and enthusiasm in working with us. We would also like to thank the Pomona College Field Methods class in Spring 2013 for their collective work that provided the initial impetus for this research. Martin Walkow inspired this project with his questions about agreement with conjoined arguments, and provided much helpful input and feedback. Finally, we would like to thank Mikayla Bactad for her work on these same topics that bolstered the conclusions reached here. 


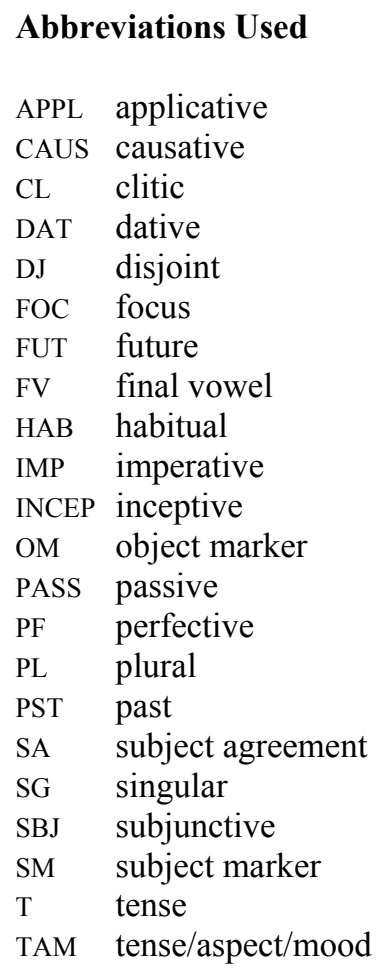

Cardinal numerals indicate Bantu Noun Class markers. Numerals combined with an indication of number marking represent person (e.g., $1 \mathrm{sg}=$ first person singular).

\section{Orthographic conventions}

The orthographic conventions we have used here are the same as those adopted in Diercks et al. (2015). An intervocalic $<\mathrm{g}>$ represents [y], an intervocalic $<\mathrm{b}>$ represents $[\beta],<\mathrm{y}>$ represents [j], $<$ ny $>$ represents [n], $<\mathrm{r}>$ represents [r] and $<\mathrm{r}$ : $>$ represents [r]. Because these are (broad) phonetic transcriptions of only single sentences, punctuation and other kinds of orthographic conventions for marking sentences are not used here. High tone is marked by an acute accent on the vowel; low tone is unmarked. Ungrammatical examples are not transcribed with tone markings. Kuria tonology is discussed in Marlo et al. (2015) and briefly in Diercks et al. (2015); in short, the recent past tense (the form in which most examples in the present paper appear) assigns a $\mathrm{H}$ tone to the third mora of the verb's macrostem (i.e., to the third mora of the verb stem including object markers, if any). The regular phonology of the language spreads a $\mathrm{H}$ tone rightward to all vowels in the phrase, up to and including the penultimate mora (in some cases spreading into the FV as well; this appears to be optional, as is $\mathrm{H}$ tone assignment in this tense when the third mora of the verb stem is phrase-final). If a $\mathrm{H}$ tone is followed by another $\mathrm{H}$ in the phrase (e.g. on a noun root, since these have initial $\mathrm{H}$ tones), the spreading will stop one mora short of the following $\mathrm{H}$, leaving a toneless mora in between that is realized with a low tone. Diercks et al. (2015) hypothesized that $\mathrm{H}$ tones do not spread from subjects into the VP, but data in the present paper indicate that such spreading does optionally occur. 


\section{References}

Ashton, Ethel O. 1944. Swahili Grammar. Harlow: Longman.

Bax, Anna and Michael Diercks. 2012. Information structure constraints on object marking in Manyika. Southern African Linguistics and Applied Language Sciences 30.2: 185-202.

Bhatt, Rajesh and Martin Walkow. 2012. Locating agreement in grammar: An argument from agreement in conjunctions. To appear in Natural Language and Linguistic Theory.

Benmamoun, E., Bhatia, A., and Polinsky, M. 2009. Closest conjunct agreement in head final languages. Linguistic Variation Yearbook 9: 67-88.

Bokamba, Eyamba. 1985 Verbal agreement as a noncyclic rule in Bantu. African Linguistics: Essays in memory of M.W.K. Semikenke, Studies in the Sciences of Language 6, 9-54. Amsterdam: John Benjamins.

Bošković, Željko. 2009. Unifying first and last conjunct agreement. Natural Language \& Linguistic Theory 27: 455-496.

Bresnan, Joan, and Sam Mchombo. 1987. Topic, pronoun, and agreement in Chichêwa. Language 63:741-782.

Cammenga, Jelle. 2004. Igikuria phonology and morphology: A Bantu language of southwest Kenya and northwest Tanzania. Köln: Rüdiger Köppe Verlag.

Citko, Barbara. 2004. Agreement asymmetries in coordinate structures. In Formal Approaches to Slavic Linguistics \# 12: the Ottawa Meeting. Ann Arbor: Michigan Slavic Publications.

Corbett, Greville and Alfred Mtenje. 1987. Gender agreement in Chichewa. Studies in African Linguistics 18.1: 1-38.

De Vos, Mark and Hazel Mitchley. 2012. Subject marking and preverbal coordination in Sesotho: A perspective from Optimality Theory. Southern African Linguistics and Applied Language Studies. 30.2: 155-170.

Diercks, Michael, Rodrigo Ranero, and Mary Paster. 2015. Evidence for a Clitic Analysis of Object Markers in Kuria. In Selected Proceedings of the 44th Annual Conference on African Linguistics, eds. Ruth Kramer, Elizabeth C. Zsiga, and One Tlale Boyer, 52-70. Somerville, MA: Cascadilla Proceedings Project.

Diercks, Michael and Justine Sikuku. 2015 Pragmatic Effects of Clitic Doubling: Two Kinds of Object Markers in Lubukusu. Ms, Pomona College and Moi University. To appear in Linguistic Variation.

Doron, Edith. 2000. VSO and left-conjunct agreement, Biblical Hebrew vs. Modern Hebrew. In The Syntax of Verb Initial Languages, eds. A. Carnie and E. Guilfoyle, 75-95. Oxford: Oxford University Press.

Fischer, Jennifer Lee. 2010. Vowel-Height Harmony in Kuria. MA Thesis, UCLA.

Givón, Talmy. 1970. The resolution of gender conflicts in Bantu conjunction: When syntax and semantics clash. In Papers from the Sixth Regional Meeting, Chicago Linguistic Society, 250261. Chicago: Chicago Linguistics Society.

Givón, Talmy. 1972. Studies in ChiBemba and Bantu Grammar. Studies in African Linguistics, Supplement 3. Los Angeles: Department of Linguistics and African Studies Center, UCLA.

Krifka, Manfred. 1995. Swahili. In Syntax: Ein internationales Handbuch zeitgenoessischer Forschung, vol. 2, eds. Joachim Jacobs, Arnim von Stechow, Wolfgang Sternefeld, and Theo Vennemann, 1397-1418. Berlin: Walter de Gruyter.

Landman, Meredith and Rodrigo Ranero. 2015. Focus Marking in Kuria. Ms, Pomona College. To appear in The Selected Proceedings of ACAL 45.

Marlo, Michael, Leonard Chacha Mwita, and Mary Paster. 2015. Problems in Kuria H tone assignment. Natural Language and Linguistic Theory 33: 251-265.

Marten, Lutz. 2000. Agreement with conjoined noun phrases in Swahili. Afrikanistische Arbeitspapiere 64: Swahili Forum VII, 75-96.

Marten, Lutz. 2005. The dynamics of agreement and conjunction. Lingua 115: 527-547. 
Marten, Lutz, Nancy Kula and Nhlanhla Thwala. 2007. Parameters of morphosyntactic variation in Bantu. Transactions of the Philological Society 105: 253-338.

Munn, A. 1999. First conjunct agreement: Against a clausal analysis. Linguistic Inquiry 30(4): 643-668.

Mwita, Chacha. 2008. Verbal tone in Kuria. Ph.D. dissertation, UCLA.

Odden, David. 1987. Predicting tone in Kikuria. In David Odden (ed.), Current approaches to African linguistics 4, 311-326. Dordrecht: Foris.

Ranero Echeverría, Rodrigo. 2014. The Syntax and Semantics of Kuria /ne-/. B.A. thesis, Pomona College.

Ranero, Rodrigo, Michael Diercks, and Mary Paster. 2015. One of these things is not like the others: Deriving clitics by both movement and Agree. Ms, Pomona College.

Riedel, Kristina. 2009. The syntax of object marking in Sambaa: A comparative Bantu perspective. Leiden University dissertation.

Roberts, L. and Wolontis, M. 1974. Conjunction and concord in Bantu. In Third Annual Conference on African Linguistics, ed. E. Voeltz, 231-242. Bloomington: Indiana University Publications.

Schadeberg, Thilo C. 1992. A Sketch of Swahili Morphology, 3rd ed. Köln: Köppe.

Seidl, A. and A. Dimitriadis. 1997. The discourse function of object marking in Swahili. In Papers from the Regional Meetings, Chicago Linguistic Society, 33.1: 373-387.

Simango, Ron. 2012. Subject marking, coordination, and noun classes in CiNsenga. Southern African Linguistics and Applied Language Studies. 30.2: 171-183.

Voeltz, E. 1971. Surface constraints and gender resolution: Some evidence from Xhosa. Studies in African Linguistics 2:37-60.

Michael Diercks

Michael.Diercks@pomona.edu

Mary Paster

Mary.Paster@pomona.edu
Submitted: 5 Dec 13

Accepted: 24 Jun 14

Revisions received: 2 May 15 